in vivo $35: 593-601(2021)$

doi:10.21873/invivo.12296

\title{
Impact of Fluoropyrimidine and Oxaliplatin-based Chemoradiotherapy in Patients With Locally Advanced Rectal Cancer
}

\author{
YUKA OKADA, TSUYOSHI OZAWA, TAMURO HAYAMA, KOHEI OHNO, MITSUO TSUKAMOTO, YOSHIHISA \\ FUKUSHIMA, RYU SHIMADA, KEIJIRO NOZAWA, KEIJI MATSUDA and YOJIRO HASHIGUCHI \\ Department of Surgery, Teikyo University School of Medicine, Tokyo, Japan
}

\begin{abstract}
Background/Aim: To evaluate the benefits of the addition of oxaliplatin $(\mathrm{OX})$ to fluoropyrimidine (FP)-based neoadjuvant chemoradiotherapy (CRT) for patients with locally advanced rectal cancers (LARCs). Patients and Methods: We performed retrospective analyses comparing the pathological complete response ( $p C R$ ) rate, overall survival $(O S)$, recurrence-free survival (RFS), and local recurrencefree survival (LRFS) between FP-based and FP+OX-based $C R T$ groups and for patients who had completed the CRT. Results: One hundred patients were included in the analyses: the $p C R$ rate, OS, RFS, and LRFS were similar between these groups. The $\mathrm{FP}+\mathrm{OX}$ group showed significantly more frequent incompleteness of the CRT compared to the FP group $(p=0.049)$. Among the patients who had completed the CRT, the FP+OX group demonstrated significantly improved LRFS compared to the FP group $(p=0.048)$. Conclusion: The addition of $O X$ to an FP regimen in neoadjuvant CRT for LARC may reduce local recurrence in patients who have achieved good compliance to CRT.
\end{abstract}

Neoadjuvant chemoradiotherapy (CRT) is a one of the standard treatments for locally advanced rectal cancer (LARC) worldwide (1-3). Fluoropyrimidine (FP)-based chemotherapy concomitant with radiotherapy (RT) is the most frequently used CRT regimen for LARC, and these agents are suggested to increase the radiosensitivity of the cancers (4-6).

This article is freely accessible online.

Correspondence to: Tsuyoshi Ozawa, MD, Ph.D., Department of Surgery, Teikyo University School of Medicine, 2-11-1 Kaga, Itabashi-ku, Tokyo 173-0003, Japan. Tel: +81 0339641211, e-mail: tsuozawa244@gmail.com

Key Words: Chemoradiotherapy, CRT, rectal cancer, oxaliplatin, SOX.
Oxaliplatin (OX) and irinotecan (IRI) are the other key chemotherapy agents which are used concomitantly with FP for colorectal cancers (CRCs), and in recent years, the effects of adding oxaliplatin or irinotecan to FP in neoadjuvant CRT settings has been evaluated in several studies including randomized controlled trials (RCTs) (7-14). The STAR-01 randomized phase III trial, which compared the overall survival (OS) between infused-fluorouracil (FU)-based CRT and infused-FU+OX-based CRT showed no significant difference between these treatments' outcomes (7). Similarly, the National Surgical Adjuvant Breast and Bowel Project (NSABP) R-04 demonstrated that the addition of OX to 5FU or capecitabine (Cape) did not improve the local control, disease-free survival (DFS), or OS rates (12). However, the phase $3 \mathrm{CAO} / \mathrm{ARO} / \mathrm{AIO}-04$ trial conducted in Germany, which compared the survival and CRT response between patients who received FU-based neoadjuvant CRT followed by FU-based adjuvant chemotherapy and patients who received FU+OX-based neoadjuvant CRT followed by FU+OX-based adjuvant chemotherapy, revealed improved DFS in patients administered the FU+OX regimen (9).

In Japan, the SHOGUN trial (a phase II study of CRT using $\mathrm{S}-1+\mathrm{OX}$ ) showed a high pathological complete response (pCR) rate of $27.3 \%$ and a good 3-year OS rate of $93 \%$, with no severe toxicity, although the sample size was small (15-17). OX was induced on days $1,8,22$, and 29 with a chemotherapy gap at day 22 , which may be one of the factors contributing to the patients' good compliance. The authors speculated that the favorable toxicity profile led to the good result compared to previous studies.

The compliance to OX treatment in the STAR-01 and NSABP R-04 studies was actually fairly low, ranging from $62 \%$ to $75 \%$. We thus hypothesized, that the addition of OX under a feasible chemotherapy regimen may have a certain benefit compared to FP alone. In this study, we retrospectively compared $\mathrm{FP}$ and $\mathrm{FP}+\mathrm{OX}$ regimens among all patients and among those who had good compliance. As we hypothesized, our results showed that in the patients who 
achieved good compliance to the $\mathrm{FP}+\mathrm{OX}$ regimen, the local recurrence rate was lower compared to the patients who received the FP-alone regimen. This is, to our knowledge, the first study showing the ability of the addition of $\mathrm{OX}$ in neoadjuvant CRT settings for rectal cancer to improve local control.

\section{Patients and Methods}

Patients. We retrospectively analyzed the clinicopathological data of 126 patients with LARCs who underwent neoadjuvant CRT and subsequent surgery at Teikyo University Hospital (Tokyo) from 2007 to 2017. Patients with non-adenocarcinoma $(n=8)$, anal fistula-related cancer $(n=1)$, inflammatory bowel disease-associated cancer $(n=1)$, or synchronous cancer in other organs $(n=1)$ were excluded. Patients for whom FP was induced and who received an IRI-based chemotherapy regimen $(n=4)$, patients in whom distant metastases were detected after neoadjuvant CRT $(\mathrm{n}=6)$, and patients who underwent non-curative surgery $(n=5)$ were also excluded (Figure 1$)$. Patients provided written informed consent for publication of their data. This study was approved by the Teikyo University ethics committee (no. 19-127). The study protocol conforms to the ethical guidelines of the 1975 Declaration of Helsinki and its later amendments.

Neoadjuvant chemoradiotherapy and surgery. Neoadjuvant CRT was performed as described (18). In summary, the total dose of radiotherapy was $50.5 \mathrm{~Gy}$, which was given in 28 fractions on weekdays. The treatment planning was done with the aid of CT scans, and the target volume included the primary tumor, anus, and lymph nodes in the mesorectum and in the pelvis (lateral lymph nodes). As the chemotherapy regimen, tegafur-uracil and leucovorin (UFT/LV), Cape, or S-1 with oxaliplatin (SOX) were administered concomitantly with radiotherapy. UFT was induced at $300 \mathrm{mg} / \mathrm{m}^{2} /$ day, Cape was at $2500 \mathrm{mg} / \mathrm{m}^{2} /$ day, and $\mathrm{S}-1$ was at $80 \mathrm{mg} / \mathrm{m}^{2} /$ day. SOX was induced as described in the SHOGUN study; S-1 was induced at 40$60 \mathrm{mg} / \mathrm{m}^{2} /$ day on days $1-5,8-12,22-26$, and 29-33, and OX was induced at $60 \mathrm{mg} /$ week on days $1,8,22$, and 29 (16).

Total meso-rectal excision (TME) was performed at approx. 6-8 weeks after completion of the neoadjuvant CRT. Post-operative surveillance was conducted at 3-month intervals with the measurement of the patients' carcinoembryonic antigen (CEA) levels, at 6-month intervals with computed tomography (CT), and at 1-year intervals with a colonoscopy.

The CRT response grade was determined pathologically based on the Japanese Society for Cancer of the Colon and Rectum guidelines (ninth edition) as follows. Grade 0: No evidence of tumor response, Grade 1: $<2 / 3$ regression of the tumor cells, Grade 2: $\geq 2 / 3$ regression of the tumor cells, Grade 3: complete regression. Grade 3 indicates a pCR, and Grades 2 and 3 were defined as good response (3).

Statistical analyses. The $\chi^{2}$ test or Fisher's exact test was used for the comparisons of categorical data, and the Wilcoxon rank sum test was used for continuous variables. The 3-year OS was defined as the period between the date of surgery and the date of death from any cause within 3 years after surgery. The 3 -year recurrence-free survival (RFS) was defined as the period between the date of surgery and the date of any tumor recurrence within 3 years after surgery. The 3-year local recurrence-free survival (LRFS) was defined as the period between the date of surgery and the date of

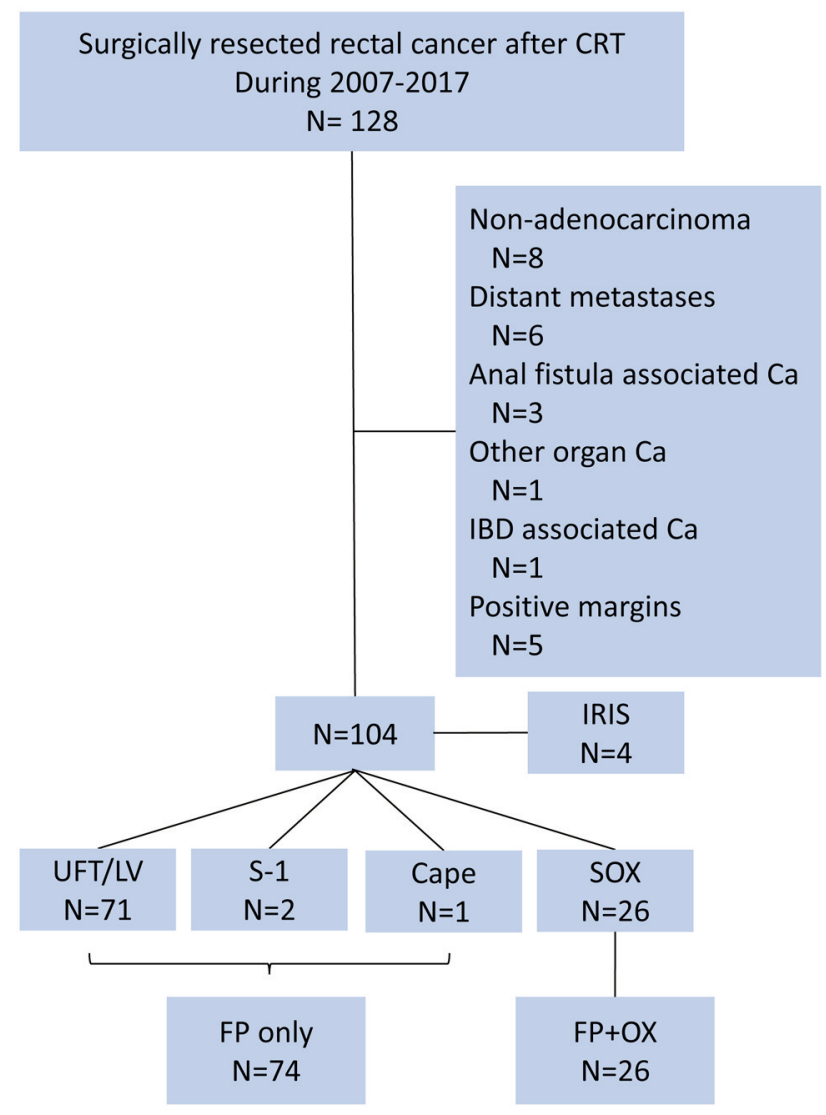

Figure 1. Flow chart illustrating inclusion and exclusion criteria of the patients in the present study.

tumor recurrence in the local region (the area in which the surgical procedures were performed) within 3 years after surgery.

We divided the patients into two groups: those who received FP alone-based CRT and those who received FP+OX-based CRT. We compared the groups' survival and clinicopathological factors. Survival was compared by determining the Kaplan-Meier curves, and the differences in survival were evaluated with the log-rank test. We defined 'incomplete CRT' as CRT with a total dose of $<80 \%$ chemotherapy and/or a total dose of $<45$ Gy radiotherapy $(19,20)$. The pre-CRT clinicopathological factors were dichotomized into two groups using Youden indexes, which were calculated by depicting the receiver-operating characteristics (ROC) curves, and factors associated with incompleteness of the neoadjuvant CRT were evaluated by logistic regression model analyses. Differences with a $p$-value of $<0.05$ were considered significant in all analyses. All statistical calculations were performed using JMP Pro 15 statistical software (SAS Institute Japan, Tokyo, Japan).

\section{Results}

The FP+OX group showed a trend toward frequent incompletion of CRT compared to the FP group. The FP group comprised 74 patients, most of whom were treated with UFT/LV ( $\mathrm{n}=70, \%)$; two patients $(3 \%)$ were treated with 
Okada et al: Impact of Oxaliplatin in CRT

Table I. Comparison of clinicopathological factors between the FP-based CRT group and FP+OX-based CRT group.

\begin{tabular}{|c|c|c|c|}
\hline Characteristics $(\mathrm{N}, \%)$ & FP-based CRT (N=74) & $\mathrm{FP}+\mathrm{OX}$-based CRT $(\mathrm{N}=26)$ & $p$-Value \\
\hline \multicolumn{4}{|l|}{ Gender } \\
\hline Male/Female & $58(78) / 16(22)$ & $18(69) / 8(31)$ & 0.425 \\
\hline \multicolumn{4}{|l|}{ Age (Years) } \\
\hline mean & 63 & 64 & 0.792 \\
\hline \multicolumn{4}{|l|}{ Distance from AV (cm) } \\
\hline$\leq 5 />5$ & $44(60) / 30(40)$ & $12(46) / 14(54)$ & 0.214 \\
\hline \multicolumn{4}{|l|}{ cStage } \\
\hline $2 / 3$ & $28(39) / 45(61)$ & $9(35) / 17(65)$ & 0.815 \\
\hline \multicolumn{4}{|l|}{ ypStage } \\
\hline $0-1 / 2 / 3$ & $31(42) / 24(32) / 19(26)$ & $9(35) / 11(42) / 6(23)$ & 0.650 \\
\hline \multicolumn{4}{|l|}{ Histology } \\
\hline Well-Mod/Por-Muc & $63(86) / 11(14)$ & $25(96) / 1(4)$ & 0.279 \\
\hline \multicolumn{4}{|l|}{ Adjuvant chemotherapy } \\
\hline Absent/Present/Unavailable & $54(73) / 20(27) / 1(1)$ & $7(38) / 16(62) / 0(0)$ & 0.004 \\
\hline \multicolumn{4}{|l|}{ Pre-CRT CEA (ng/ml) } \\
\hline$<5 / \geq 5$ & $44(54) / 30(46)$ & $15(58) / 11(42)$ & 0.739 \\
\hline
\end{tabular}

AV: Anal verge; CEA: carcinoembryonic antigen. Bold values indicate statistical significance.

S-1, and one patient (1\%) was treated with Cape. The $\mathrm{FP}+\mathrm{OX}$ group comprised 26 patients, all of whom received the SOX regimen (Figure 1). The median post-surgery follow-up period was 1,937 days (range=45-4931 days). During the follow-up period, recurrence at distant sites occurred in 32 patients (32\%), and recurrences in the local region were noted in 13 patients $(13 \%)$.

Table I summarizes the clinicopathological factors of each CRT group. The $\mathrm{FP}+\mathrm{OX}$ group received adjuvant chemotherapy (mostly UFT/LV) significantly more frequently compared to the FP group (62\% vs. $27 \%, p=0.004)$. Compliance to the regimen was significantly better in the patients who received the FP regimen compared to those who received the $\mathrm{FP}+\mathrm{OX}$ regimen $(95 \%$ vs. $81 \%, p=0.049)$. The other clinicopathological factors were not significantly different between the two groups. The details of the cause of incompleteness of the CRT are provided in Table II.

The FP group and FP+OX group showed no significant difference in the pCR rate $(9 \% v s .15 \%, p=0.470)$ or the good response rate to CRT (55\% vs. $46 \%$, respectively; $p=0.416)$. Although the 3 -year OS (89\% vs. 96\%, $p=0.153)$ and 3-year RFS (65\% vs. 69\%, $p=0.651)$ were similar between the two groups, the FP+OX group showed a trend toward better LRFS compared to the FP group (84\% vs. $9 \%$, $p=0.060$ ) (Figure 2A-C).

The FP+OX group demonstrated improved local recurrencefree survival compared to the FP group among patients who had good compliance to neoadjuvant CRT. We also compared the survival and CRT-response rate among the patients who completed the neoadjuvant CRT. The FP group and $\mathrm{FP}+\mathrm{OX}$ group showed no significant difference in the
Table II. The reasons for incompleteness of the CRT in each group.

\begin{tabular}{lcc}
\hline Groups & Reason for incompleteness & $\mathrm{N}$ \\
\hline FP-based CRT & Diarrhea & 1 \\
& Allergy (drug eruption) & 1 \\
& Thrombocytopenia & 1 \\
FP+OX-based CRT & Appendicitis & 1 \\
& Neutropenia & 3 \\
& Allergy (drug eruption) & 1 \\
& Recto-vaginal fistula & 1 \\
\hline
\end{tabular}

pCR rate $(10 \%$ vs. $19 \%, p=0.270)$ or the good response rate to CRT ( $54 \%$ vs. $48 \%$, respectively; $p=0.592)$. Regarding survival, the 3 -year OS (90\% vs. $100 \%, p=0.144)$ and 3 -year RFS $(64 \%$ vs. $71 \%, p=0.439)$ were similar between the FP and $\mathrm{FP}+\mathrm{OX}$ groups, but the LRFS was significantly better in the $\mathrm{FP}+\mathrm{OX}$ group compared to the FP group (83\% vs. $100 \%$, respectively; $p=0.048$ ) (Figure $2 \mathrm{D}-\mathrm{F}$ ).

In the FP+OX group, incompleteness of neoadjuvant CRT was suggested to be associated with poor OS and LRFS. We then compared the survival between the groups with and without good compliance to the CRT in each chemotherapy regimen. In the FP group, the patients in the CRT-complete group and those in the CRT-incomplete group showed no significant difference in the 3-year OS $(75 \%$ vs. $90 \%$, $p=0.316$ ), 3-year RFS (67\% vs. 64\%, $p=0.696$ ), or 3-year LRFS (100\% vs. 83\%, respectively; $p=0.413$ ) (Figure 3A$\mathrm{C})$. In the $\mathrm{FP}+\mathrm{OX}$ group, the 3 -year RFS rates $(60 \%$ vs. $71 \%$, $p=0.424$ ) were similar between the two groups; however, the 
A

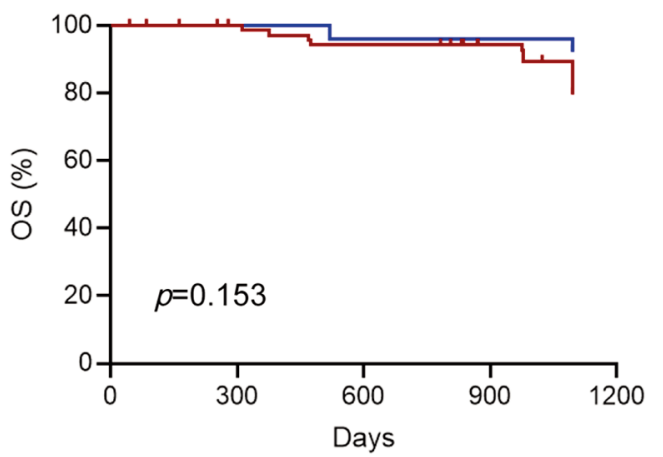

No.at risk

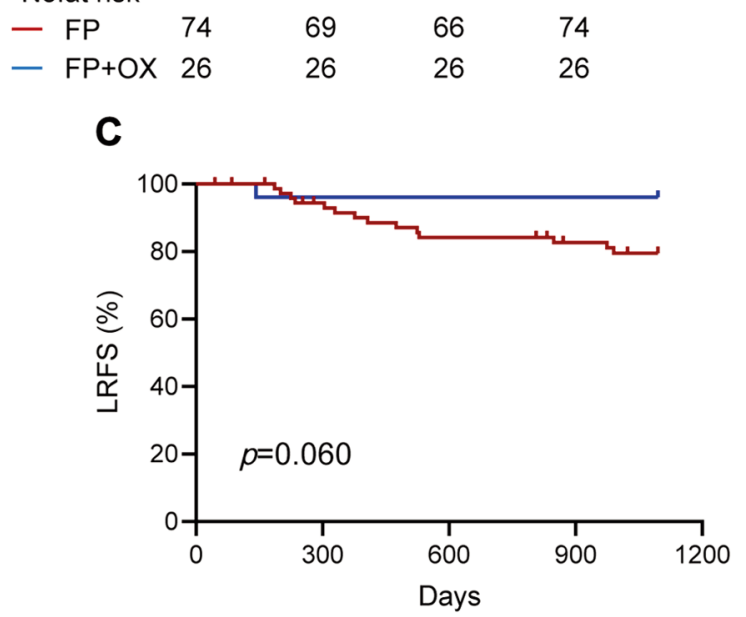

No.at risk

$\begin{array}{lllll}- \text { FP } & 74 & 66 & 59 & 54 \\ \text { - FP+OX } & 26 & 26 & 26 & 26\end{array}$

E

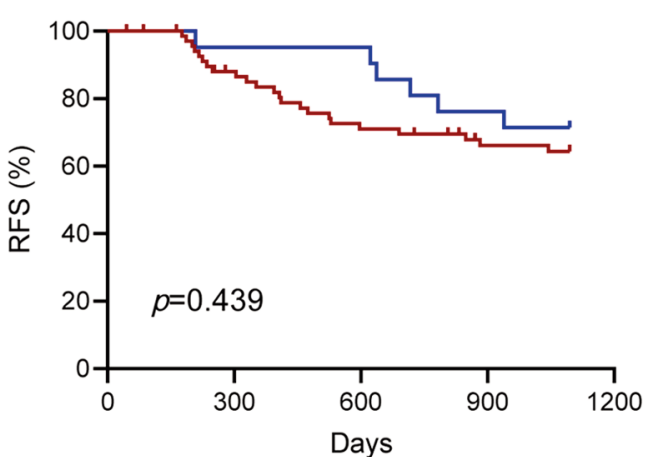

B

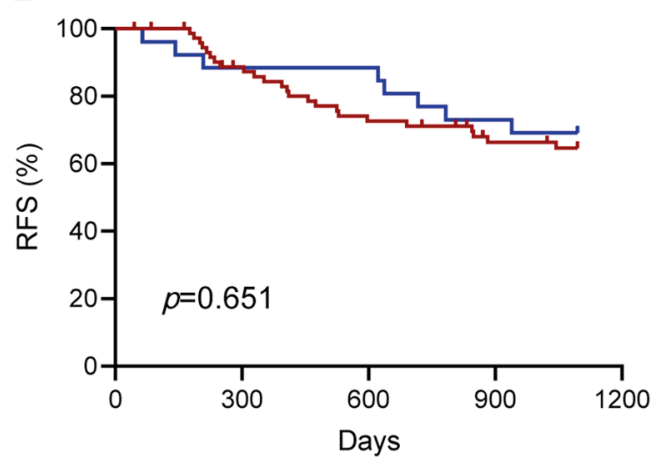

No.at risk

$\begin{array}{lllll}- \text { FP } & 74 & 62 & 50 & 41\end{array}$

$\begin{array}{lllll}- & \text { FP+OX } & 26 & 24 & 24\end{array}$

D

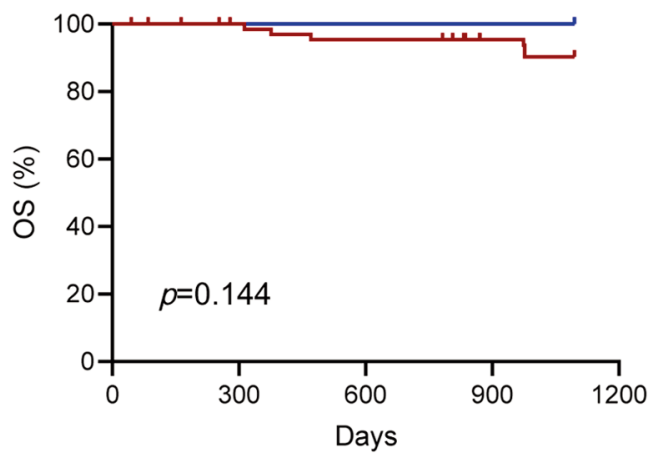

No.at risk

$\begin{array}{lllll}\text { - FP } & 70 & 66 & 63 & 57\end{array}$

$\begin{array}{lllll}\text { FP+OX } & 21 & 21 & 21 & 21\end{array}$

$\mathbf{F}$

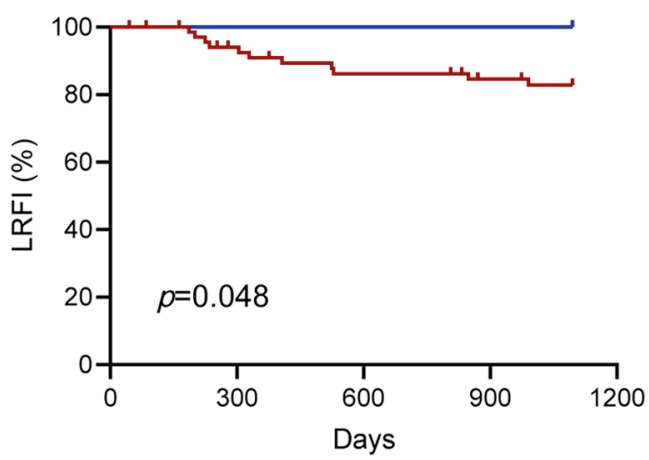

No.at risk

$\begin{array}{lllll}\text { - FP } & 70 & 62 & 56 & 51 \\ - \text { FP+OX } & 21 & 21 & 21 & 21\end{array}$

\section{No.at risk}

$\begin{array}{lllll}- \text { FP } & 70 & 58 & 47 & 39 \\ - \text { FP+OX } & 21 & 21 & 21 & 17\end{array}$

Figure 2. Kaplan-Meier curves showing overall survival, recurrence-free survival, and local recurrence-free survival in fluoropyrimidine-based chemoradiotherapy group and fluoropyrimidine and oxaliplatin-based chemoradiotherapy group. A) The FP-based CRT group and the FP+OXbased CRT group showed similar 3-year OS $(p=0.153)$. B) The FP-based CRT group and the FP+OX-based CRT group showed similar 3-year RFS ( $p=0.651) . C)$ The FP+OX-based CRT group showed improved 3-year LRFS compared to the FP-based CRT group, although statistically not significant $(p=0.060)$. D) The FP-based CRT group and the FP+OX-based CRT group showed similar 3-year OS among patients who had completed the CRT (p=0.144). E) The FP-based CRT group and the FP+OX-based CRT group showed similar 3-year RFS among the patients who had completed the CRT ( $p=0.439)$. F) The FP+OX-based CRT group showed significantly improved 3-year LRFS compared to the FP-based CRT group among the patients who had completed the CRT ( $p=0.048)$. 
A

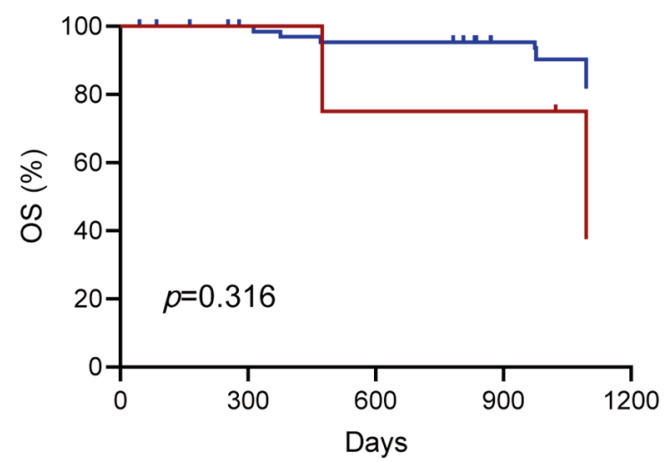

No.at risk

$\begin{array}{lcccc}\text { - Comp } & 70 & 66 & 63 & 57 \\ \text { - Incomp } & 4 & 4 & 4 & 4\end{array}$

C

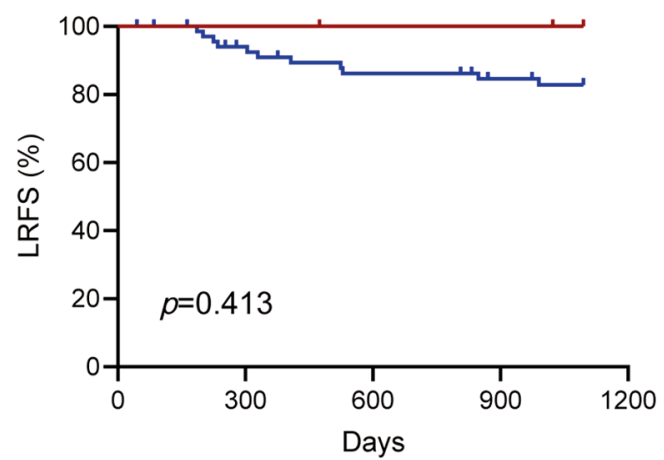

No.at risk

$\begin{array}{lcccc}\text { - Comp } & 70 & 62 & 56 & 51 \\ \text { - Incomp } & 4 & 4 & 4 & 4\end{array}$

E

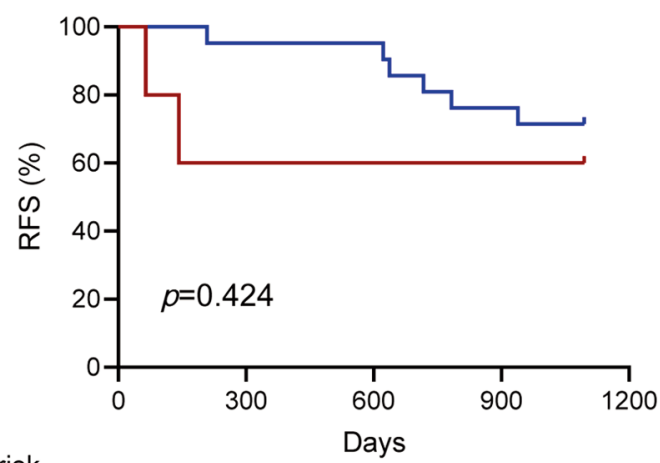

No.at risk

- Comp

- Incomp
B

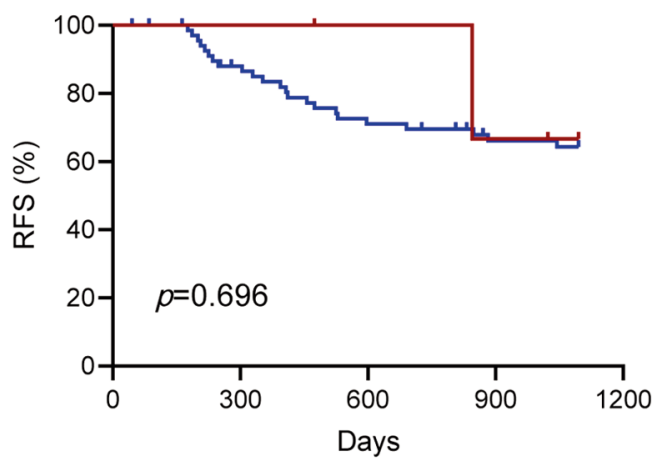

No.at risk

$\begin{array}{lllll}\text { - Comp } & 70 & 58 & 47 & 39\end{array}$

$\begin{array}{lllll}\text { - Incomp } 4 & 4 & 4 & 4\end{array}$

D

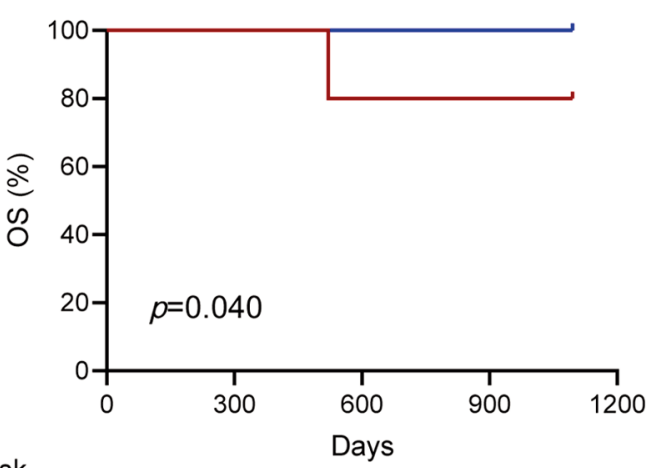

No.at risk

$\begin{array}{lllll}\text { - Comp } & 21 & 21 & 21 & 21\end{array}$

- Incomp $55 \quad 5 \quad 5 \quad 5$

$\mathbf{F}$

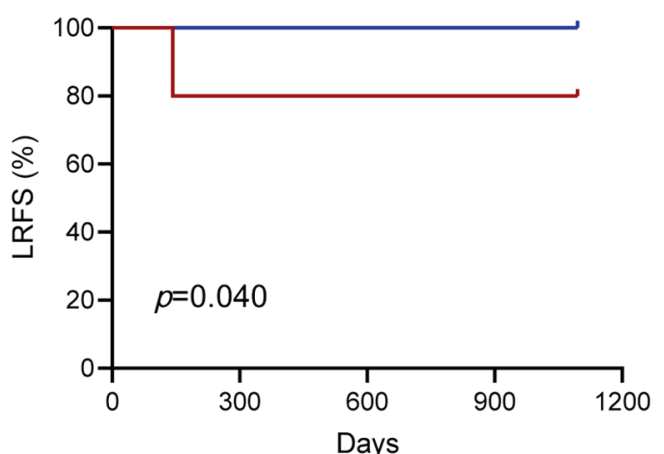

No.at risk

$\begin{array}{lcccc}\text { - Comp } & 21 & 21 & 21 & 21 \\ \text { - Incomp } & 5 & 5 & 5 & 5\end{array}$

Figure 3. Kaplan-Meier curves showing overall survival, recurrence-free survival, and local recurrence-free survival in fluoropyrimidine and oxaliplatin-based chemoradiotherapy-complete group and fluoropyrimidine and oxaliplatin-based chemoradiotherapy-incomplete group. A) The CRT-complete patients showed significantly improved 3-year OS compared to the CRT-incomplete patients $(p=0.040)$ in FP-based CRT patients. $B)$ The CRT-complete group and the CRT-incomplete group showed similar 3-year RFS ( $p=0.424)$ in FP-based CRT patients. $C)$ The CRT-complete patients showed significantly improved 3-year LRFS compared to the CRT-incomplete patients $(p=0.040)$ in FP-based CRT patients. D) The CRTcomplete patients showed significantly improved 3-year OS compared to the CRT-incomplete patients $(p=0.040)$ in FP+OX-based CRT patients. E) The CRT-complete group and the CRT-incomplete group showed similar 3-year RFS $(p=0.424)$ in FP+OX-based CRT patients. F) The CRTcomplete patients showed significantly improved 3-year LRFS compared to the CRT-incomplete patients $(p=0.040)$ in FP+OX-based CRT patients. 
A

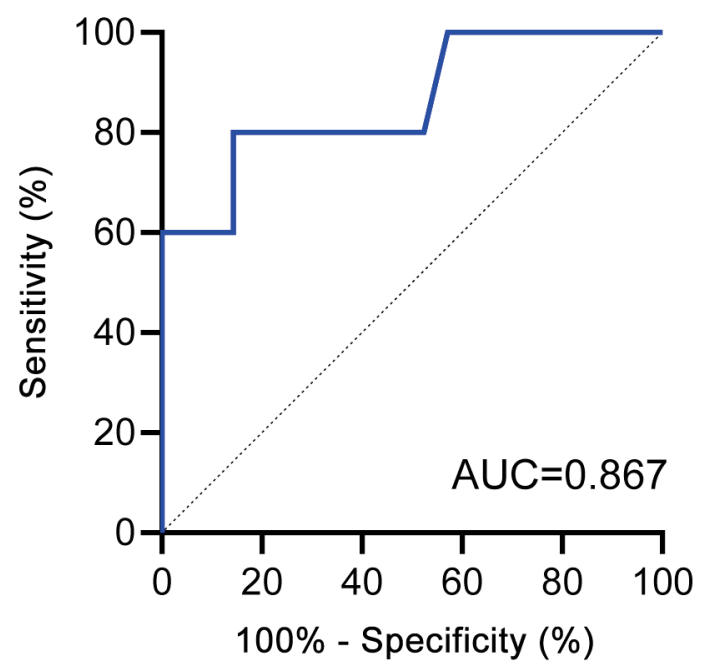

B

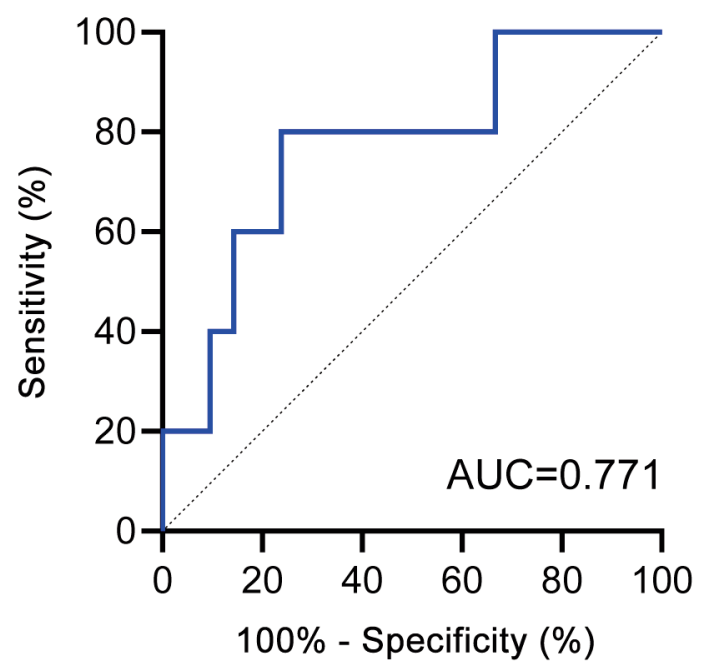

Figure 4. Receiver operating characteristics curves of pre-chemoradiotherapy neutrophil count and lymphocyte count to predict the incompleteness of the chemoradiotherapy. A) Area under the curve was 0.867 with neutrophil count. B) Area under the curve was 0.771 with lymphocyte count.

Table III. Logistic regression analyses evaluating the factors associated with the treatment incompleteness in the fluoropyrimidine and oxaliplatin $(F P+O X)$-based chemoradiotherapy $(C R T)$ group.

\begin{tabular}{|c|c|c|c|}
\hline \multicolumn{4}{|l|}{ Analyses } \\
\hline Variables & OR & $95 \% \mathrm{CI}$ & $p$-Value \\
\hline \multicolumn{4}{|l|}{ Gender } \\
\hline Male/Female & 0.60 & $0.08-4.54$ & 0.621 \\
\hline \multicolumn{4}{|l|}{ Age (Years) } \\
\hline$\geq 65 /<65$ & 2.44 & $0.33-17.9$ & 0.381 \\
\hline \multicolumn{4}{|l|}{ cStage } \\
\hline III/II & 0.27 & $0.03-2.02$ & 0.201 \\
\hline \multicolumn{4}{|l|}{ CEA (ng/ml) } \\
\hline$\geq 5 /<5$ & 2.44 & $0.33-17.9$ & 0.381 \\
\hline \multicolumn{4}{|l|}{ WBC $(/ \mu \mathrm{l})$} \\
\hline$\geq 6300 /<6300$ & - & - & 0.996 \\
\hline \multicolumn{4}{|l|}{ Neutrophil $(/ \mu \mathrm{l})$} \\
\hline$\geq 4914 /<4914$ & 24.0 & $1.95-295$ & 0.013 \\
\hline \multicolumn{4}{|c|}{ Lymphocyte $(/ \mu \mathrm{l})$} \\
\hline$\geq 1352 /<1352$ & 0.08 & $0.01-0.87$ & 0.038 \\
\hline \multicolumn{4}{|l|}{ Monocyte $(/ \mu \mathrm{l})$} \\
\hline$\geq 396 /<396$ & 8.00 & $0.75-85.7$ & 0.086 \\
\hline \multicolumn{4}{|l|}{ Platelet $(104 / \mu \mathrm{l})$} \\
\hline$\geq 25.4 /<25.4$ & 0.19 & $0.02-1.98$ & 0.164 \\
\hline \multicolumn{4}{|l|}{ CRP (mg/dl) } \\
\hline$\geq 2.14 /<2.14$ & - & - & 0.993 \\
\hline \multicolumn{4}{|c|}{ Hemoglobin $(\mathrm{g} / \mathrm{dl})$} \\
\hline$\geq 10.1 /<10.1$ & 0.25 & $0.03-2.18$ & 0.210 \\
\hline \multicolumn{4}{|l|}{ Albumin (g/dL) } \\
\hline$\geq 3.8 /<3.8$ & 0.21 & $0.03-1.62$ & 0.134 \\
\hline \multicolumn{4}{|c|}{ Cholesterol (mg/dl) } \\
\hline$\geq 210 /<210$ & 3.00 & $0.40-22.3$ & 0.283 \\
\hline
\end{tabular}

OR: Odds ratio; CI: confidence interval; CEA: carcinoembryonic antigen; CRP: C-reacted protein. Bold values indicate statistical significance.
CRT-complete patients showed significantly improved 3-year OS (80\% vs. $100 \%, p=0.040)$ and 3-year LRFS (80\% vs. $100 \%, p=0.040)$ compared to the CRT-incomplete patients (Figure 3D-F).

In the FP+OX group, the pre-CRT neutrophil count was a good marker to predict incompleteness of the neoadjuvant CRT. Because the completeness of the pre-CRT was suggested to be one of the key factors to achieve the effectiveness of $\mathrm{FP}+\mathrm{OX}$-based CRT, we investigated whether any of the pre-neoadjuvant CRT clinical factors could predict the incompleteness of the CRT in the patients who had received the $\mathrm{FP}+\mathrm{OX}$-based CRT. The results of the logistic regression analyses demonstrated that the pre-CRT neutrophil count $(\geq 4,914)$ [odds ratio $(\mathrm{OR})=24.0,95 \%$ confidence interval $(\mathrm{CI})=1.95-295, \quad p=0.013]$ and lymphocyte count $(\geq 1,352)(\mathrm{OR}=0.08,95 \% \mathrm{CI}=0.01-0.87$, $p=0.038)$ were significantly associated with incompleteness of the CRT (Table III). The ROC analysis revealed that in the $\mathrm{FP}+\mathrm{OX}$ group, the pre-CRT neutrophil count had an area under the curve (AUC) of 0.867 and the pre-CRT lymphocyte count had an AUC of 0.771 to predict the incompleteness of the CRT (Figure 4A and B).

\section{Discussion}

We evaluated the benefit of adding OX to FP-based neoadjuvant CRT in LARC patients. The results of our retrospective analyses demonstrated that addition of $\mathrm{OX}$ improved the local recurrence-free survival in patients who achieved good compliance in their scheduled neoadjuvant CRT. 
Several RCTs have compared FP-based CRT and FP+OXbased CRT in rectal cancer patients, and most of the RCTs failed to observe any benefit from the addition of OX $(7,8$, $10,12)$. One of the explanations for the discrepancy between these reported results and our present findings may be due to the low compliance to the FP+OX regimen. In the STAR01 trial comparing FU-based CRT vs. FU+OX-based CRT, although the $\mathrm{pCR}$ rate and OS were similar between the two regimens, the percentage of patients who received a $>80 \%$ dose of the FU+OX regimen was only $75 \%$ (7). Moreover, the authors did not mention the local recurrence rate. Similarly, in the NSABP R-04 trial comparing 5-FU/Capebased CRT with 5-FU/Cape+OX-based CRT, the compliance for the OX regimen was only $62 \%$ with Cape and $69 \%$ with 5-FU (12).

The CAO/ARO/AIO-04 study was the only trial that demonstrated a benefit from the addition of OX; it compared FU-based CRT and FU+OX-based CRT (9). The patients who received the $\mathrm{FU}+\mathrm{OX}$-based $\mathrm{CRT}$ showed a higher $\mathrm{pCR}$ rate and better DFS compared to the patients who received the FUbased CRT. At 3 years, the cumulative incidence of local recurrence was $4.6 \%$ in the $\mathrm{FU}+\mathrm{OX}$-based CRT group and $2.9 \%$ in the FU-based CRT group, demonstrating the superiority of the FU+OX-based regimen. The compliance of the chemotherapy in that trial was fairly good, and $95.4 \%$ of the patients received $>80 \%$ of the planned OX. It was thus suggested, that the compliance to a CRT regimen may be one of the key factors to achieve the benefit of the addition of OX.

Freischlag et al. demonstrated that achieving a complete radiation dose (45-50.4 Gy) was associated with lower risk of long-term mortality in patients with stage II and III rectal cancer who received neoadjuvant CRT (19). Moreover, a post-hoc analysis of the CAO/ARO/AIO-04 trial results evaluating the association between treatment adherence and oncologic outcomes showed that the patients with LARCs who had complete adherence to the neoadjuvant CRT, achieved significantly improved 3-year DFS compared to the patients with a reduced dose of neoadjuvant CRT (20). Consistent with the findings of that analysis, our present findings demonstrated that in the $\mathrm{FP}+\mathrm{OX}$ group, the $\mathrm{OS}$ and LRFS were significantly superior in the patients who had completed their CRT compared to those who had not.

Moreover, because our results demonstrated that the adherence to CRT may be an important factor in the benefit of the addition of OX, we investigated factors associated with treatment failure in the patients who received the $\mathrm{FP}+\mathrm{OX}$-based CRT. Intriguingly, the pre-CRT neutrophil count and lymphocyte count were revealed to have a high potential to predict treatment failure in these populations. It has been reported that molecular factors including several single nucleotide polymorphisms (SNPs) can be used as markers to predict the toxicity of OX-based chemotherapy (21-23). However, these markers are costly and difficult to evaluate widely in institutional laboratories. It is easy and inexpensive to measure patients' neutrophil and lymphocyte counts in most institutions.

We acknowledge several study limitations. This was a retrospective cohort study, and a large prospective study is necessary. The FP group included heterogenous chemotherapy regimens, mostly UFT/LV. Comparisons of S-1 versus SOX as chemotherapy regimens in neoadjuvant CRT settings could determine the actual benefit of the addition of $\mathrm{OX}$.

In conclusion, our study demonstrated that the addition of OX to an FP regimen in neoadjuvant CRT settings for rectal cancer may have the potential to reduce local recurrence in patients who achieved good compliance to the CRT. In addition, the pre-CRT neutrophil count can be used a marker to predict the completeness of CRT in patients who received an $\mathrm{FP}+\mathrm{OX}$ regimen.

\section{Conflicts of Interest}

The Authors declare no conflicts of interest in relation to this study.

\section{Authors' Contributions}

Y.O was involved in the analysis and interpretation of data and the drafting of the manuscript. T.O was involved in the study concept and design, the analysis and interpretation of data, and the drafting of the manuscript. K.O, M.T, Y.F, and R.S were involved in the acquisition of data. T.H, K.M, and K.N were involved in the critical revision of the manuscript for important intellectual content and material support. Y.H was involved in the study concept and study supervision.

\section{Acknowledgements}

This study was supported by a Grant-in-Aid for Young Scientists from the Japan Society for the Promotion of Science (JSPS KAKENHI grant no. JP19K16810).

\section{References}

1 Wong RK, Tandan V, De Silva S and Figueredo A: Pre-operative radiotherapy and curative surgery for the management of localized rectal carcinoma. Cochrane Database Syst Rev 2: CD002102, 2007. PMID: 17443515. DOI: 10.1002/14651858.CD002102.pub2

2 Beppu N, Yanagi H and Tomita N: A review of preoperative chemoradiotherapy for lower rectal cancer. J Anus Rectum Colon 1(3): 65-73, 2017. PMID: 31583303. DOI: 10.23922/jarc.2017-013

3 Hashiguchi Y, Muro K, Saito Y, Ito Y, Ajioka Y, Hamaguchi T, Hasegawa $K$, Hotta $K$, Ishida $H$, Ishiguro $M$, Ishihara $S$, Kanemitsu Y, Kinugasa Y, Murofushi K, Nakajima TE, Oka S, Tanaka T, Taniguchi H, Tsuji A, Uehara K, Ueno H, Yamanaka T, Yamazaki K, Yoshida M, Yoshino T, Itabashi M, Sakamaki K, Sano K, Shimada Y, Tanaka S, Uetake H, Yamaguchi S, Yamaguchi N, Kobayashi H, Matsuda K, Kotake K, Sugihara K, Japanese Society for Cancer of the C and Rectum: Japanese society for cancer of the colon and rectum (jsccr) guidelines 2019 for the treatment of colorectal cancer. Int J Clin Oncol, 2019. PMID: 31203527. DOI: 10.1007/s10147-019-01485-Z 
4 Benson AB, Venook AP, Al-Hawary MM, Cederquist L, Chen YJ, Ciombor KK, Cohen S, Cooper HS, Deming D, Engstrom PF, Grem JL, Grothey A, Hochster HS, Hoffe S, Hunt S, Kamel A, Kirilcuk N, Krishnamurthi S, Messersmith WA, Meyerhardt J, Mulcahy MF, Murphy JD, Nurkin S, Saltz L, Sharma S, Shibata D, Skibber JM, Sofocleous CT, Stoffel EM, Stotsky-Himelfarb E, Willett CG, Wuthrick E, Gregory KM, Gurski L and FreedmanCass DA: Rectal cancer, version 2.2018, nccn clinical practice guidelines in oncology. J Natl Compr Canc Netw 16(7): 874-901, 2018. PMID: 30006429. DOI: 10.6004/jncen.2018.0061

5 Martin LK and Bekaii-Saab T: Optimizing neoadjuvant therapy for rectal cancer with oxaliplatin. J Natl Compr Canc Netw 11(3): 298-307; quiz 307, 2013. PMID: 23486456. DOI: $10.6004 /$ jnccn.2013.0041

6 Taira T, Nozawa H, Kawai K, Sasaki K, Murono K, Kaneko M, Emoto S, Iida Y, Ishii H, Yokoyama Y, Anzai H, Sonoda H and Ishihara S: Oncological outcomes of pathological t1 lower rectal cancer patients with or without preoperative chemoradiotherapy. In Vivo 34(6): 3559-3564, 2020. PMID: 33144468. DOI: 10.21873/invivo.12199

7 Aschele C, Cionini L, Lonardi S, Pinto C, Cordio S, Rosati G, Artale S, Tagliagambe A, Ambrosini G, Rosetti P, Bonetti A, Negru ME, Tronconi MC, Luppi G, Silvano G, Corsi DC, Bochicchio AM, Chiaulon G, Gallo M and Boni L: Primary tumor response to preoperative chemoradiation with or without oxaliplatin in locally advanced rectal cancer: Pathologic results of the star-01 randomized phase iii trial. J Clin Oncol 29(20): 27732780, 2011. PMID: 21606427. DOI: 10.1200/JCO.2010.34.4911

8 Gerard JP, Azria D, Gourgou-Bourgade S, Martel-Lafay I, Hennequin C, Etienne PL, Vendrely V, Francois E, de La Roche G, Bouche O, Mirabel X, Denis B, Mineur L, Berdah JF, Mahe MA, Becouarn Y, Dupuis O, Lledo G, Seitz JF, Bedenne L, Juzyna B and Conroy T: Clinical outcome of the accord 12/0405 prodige 2 randomized trial in rectal cancer. J Clin Oncol 30(36): 45584565, 2012. PMID: 23109696. DOI: 10.1200/JCO.2012.42.8771

9 Rödel C, Graeven U, Fietkau R, Hohenberger W, Hothorn T, Arnold D, Hofheinz R-D, Ghadimi M, Wolff HA, LangWelzenbach M, Raab H-R, Wittekind C, Ströbel P, Staib L, Wilhelm M, Grabenbauer GG, Hoffmanns H, Lindemann F, Schlenska-Lange A, Folprecht G, Sauer R and Liersch T: Oxaliplatin added to fluorouracil-based preoperative chemoradiotherapy and postoperative chemotherapy of locally advanced rectal cancer (the german cao/aro/aio-04 study): Final results of the multicentre, open-label, randomised, phase 3 trial. Lancet Oncol 16(8): 979-989, 2015. PMID: 26189067. DOI: 10.1016/s14702045(15)00159-X

10 Deng Y, Chi P, Lan P, Wang L, Chen W, Cui L, Chen D, Cao J, Wei H, Peng X, Huang Z, Cai G, Zhao R, Huang Z, Xu L, Zhou H, Wei Y, Zhang H, Zheng J, Huang Y, Zhou Z, Cai Y, Kang L, Huang M, Peng J, Ren D and Wang J: Modified folfox6 with or without radiation versus fluorouracil and leucovorin with radiation in neoadjuvant treatment of locally advanced rectal cancer: Initial results of the chinese fowarc multicenter, open-label, randomized three-arm phase iii trial. J Clin Oncol 34(27): 3300-3307, 2016. PMID: 27480145. DOI: 10.1200/JCO.2016.66.6198

11 Azria D, Doyen J, Jarlier M, Martel-Lafay I, Hennequin C, Etienne P, Vendrely V, Francois E, de La Roche G, Bouche O, Mirabel X, Denis B, Mineur L, Berdah J, Mahe M, Becouarn Y, Dupuis O, Lledo G, Seitz J, Bedenne L, Gourgou-Bourgade S, Juzyna B, Conroy T and Gerard J: Late toxicities and clinical outcome at 5 years of the accord 12/0405-prodige 02 trial comparing two neoadjuvant chemoradiotherapy regimens for intermediate-risk rectal cancer. Ann Oncol 28(10): 2436-2442, 2017. PMID: 28961836. DOI: 10.1093/annonc/mdx351

12 Allegra CJ, Yothers G, O'Connell MJ, Beart RW, Wozniak TF, Pitot HC, Shields AF, Landry JC, Ryan DP, Arora A, Evans LS, Bahary N, Soori G, Eakle JF, Robertson JM, Moore DF Jr., Mullane MR, Marchello BT, Ward PJ, Sharif S, Roh MS and Wolmark N: Neoadjuvant 5-fu or capecitabine plus radiation with or without oxaliplatin in rectal cancer patients: A phase III randomized clinical trial. J Natl Cancer Inst 107(11), 2015. PMID: 26374429. DOI: 10.1093/jnci/djv248

13 Kawai K, Sunami E, Hata K, Tanaka T, Nishikawa T, Otani K, Sasaki K and Nozawa H: Phase i/ii study of preoperative chemoradiotherapy with tegafiri for locally advanced rectal cancer. Clin Colorectal Cancer 17(3): 240-246, 2018. PMID: 29934092. DOI: 10.1016/j.clcc.2018.05.010

14 Gollins S, West N, Sebag-Montefiore D, Myint AS, Saunders M, Susnerwala S, Quirke P, Essapen S, Samuel L, Sizer B, Worlding J, Southward K, Hemmings G, Tinkler-Hundal E, Taylor M, Bottomley D, Chambers P, Lawrie E, Lopes A and Beare S: Preoperative chemoradiation with capecitabine, irinotecan and cetuximab in rectal cancer: Significance of pre-treatment and post-resection RAS mutations. Br J Cancer 117(9): 1286-1294, 2017. PMID: 28859058. DOI: 10.1038/bjc.2017.294

15 Ishihara S, Matsusaka S, Kondo K, Horie H, Uehara K, Oguchi M, Murofushi K, Ueno M, Mizunuma N, Shinbo T, Kato D, Okuda J, Hashiguchi Y, Nakazawa M, Sunami E, Kawai K, Yamashita H, Okada T, Ishikawa Y, Nakajima T and Watanabe $\mathrm{T}$ : A phase I dose escalation study of oxaliplatin plus oral s-1 and pelvic radiation in patients with locally advanced rectal cancer (shogun trial). Radiat Oncol 10: 24, 2015. PMID: 25612635. DOI: 10.1186/s13014-015-0333-8

16 Kondo K, Matsusaka S, Ishihara S, Horie H, Uehara K, Oguchi M, Murafushi K, Ueno M, Mizunuma N, Shimbo T, Kato D, Okuda J, Hashiguchi Y, Nakazawa M, Sunami E, Kawai K, Yamashita H, Okada T, Ishikawa Y, Fujii M and Nakajima T: Long-term results of a multicenter phase ii study of preoperative chemoradiotherapy with s-1 plus oxaliplatin for locally advanced rectal cancer (jaccro cc-04: Shogun trial). Radiother Oncol 134: 199-203, 2019. PMID: 31005216, DOI: 10.1016/j.radonc. 2019.02.006

17 Matsusaka S, Ishihara S, Kondo K, Horie H, Uehara K, Oguchi M, Murofushi K, Ueno M, Mizunuma N, Shimbo T, Kato D, Okuda J, Hashiguchi Y, Nakazawa M, Sunami E, Kawai K, Yamashita H, Okada T, Ishikawa Y, Nakajima T and Watanabe T: A multicenter phase ii study of preoperative chemoradiotherapy with s-1 plus oxaliplatin for locally advanced rectal cancer (shogun trial). Radiother Oncol 116(2): 209-213, 2015. PMID: 26337743. DOI: $10.1016 /$ j.radonc.2015.08.002

18 Kiyomatsu T, Watanabe T, Muto T and Nagawa H: The 4-portal technique decreases adverse effects in preoperative radiotherapy for advanced rectal cancer: Comparison between the 2-portal and the 4-portal techniques. Am J Surg 194(4): 542-548, 2007. PMID: 17826076. DOI: 10.1016/j.amjsurg.2007.01.030

19 Freischlag K, Sun Z, Adam MA, Kim J, Palta M, Czito BG, Migaly $\mathrm{J}$ and Mantyh CR: Association between incomplete neoadjuvant radiotherapy and survival for patients with locally advanced rectal cancer. JAMA Surg 152(6): 558-564, 2017. PMID: DOI: 10.1001/jamasurg.2017.0010 
20 Diefenhardt M, Ludmir EB, Hofheinz RD, Ghadimi M, Minsky BD, Rodel C and Fokas E: Association of treatment adherence with oncologic outcomes for patients with rectal cancer: A post hoc analysis of the cao/aro/aio-04 phase 3 randomized clinical trial. JAMA Oncol 6(9): 1416-1421, 2020. PMID: 32644104. DOI: 10.1001/jamaoncol.2020.2394

21 Chua W, Kho PS, Moore MM, Charles KA and Clarke SJ: Clinical, laboratory and molecular factors predicting chemotherapy efficacy and toxicity in colorectal cancer. Crit Rev Oncol Hematol 79(3): 224-250, 2011. PMID: 20719530. DOI: 10.1016/j.critrevonc.2010.07.012

22 Yildirim $\mathrm{N}$ and Cengiz M: Predictive clinical factors of chronic peripheral neuropathy induced by oxaliplatin. Support Care
Cancer 28(10): 4781-4788, 2020. PMID: 31974772. DOI: 10.1007/s00520-020-05319-x

23 Gonzalez A, Walker EJ, Van Loon K, Cinar P and Atreya CE: Postoperative exacerbation of oxaliplatin-induced neurotoxicity in gastrointestinal cancers: A case series. Anticancer Res 40(2): 865871, 2020. PMID: 32014930. DOI: 10.21873/anticanres.14019

Received October 25, 2020

Revised November 10, 2020

Accepted November 11, 2020 